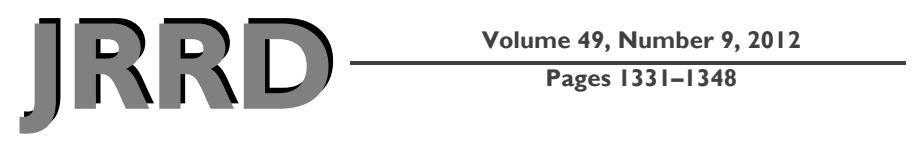

\title{
Determining skill level in myoelectric prosthesis use with multiple outcome measures
}

\author{
Hanneke Bouwsema, MSc; ${ }^{1 *}$ Peter J. Kyberd, PhD; ${ }^{2}$ Wendy Hill, BScOT; ${ }^{2}$ Corry K. van der Sluis, MD, PhD; ${ }^{3}$ \\ Raoul M. Bongers, PhD $^{1}$ \\ ${ }^{1}$ Center for Human Movement Sciences, University of Groningen, University Medical Center Groningen, Groningen, \\ The Netherlands; ${ }^{2}$ Institute of Biomedical Engineering, University of New Brunswick, Fredericton, Canada; ${ }^{3}$ Center \\ for Rehabilitation, University of Groningen, University Medical Center Groningen, Groningen, The Netherlands
}

\begin{abstract}
To obtain more insight into how the skill level of an upper-limb myoelectric prosthesis user is composed, the current study aimed to (1) portray prosthetic handling at different levels of description, (2) relate results of the clinical level to kinematic measures, and (3) identify specific parameters in these measures that characterize the skill level of a prosthesis user. Six experienced transradial myoelectric prosthesis users performed a clinical test (Southampton Hand Assessment Procedure [SHAP]) and two grasping tasks. Kinematic measures were end point kinematics, joint angles, grasp force control, and gaze behavior. The results of the clinical and kinematic measures were in broad agreement with each other. Participants who scored higher on the SHAP showed overall better performance on the kinematic measures. They had smaller movement times, had better grip force control, and needed less visual attention on the hand. The results showed that time was a key parameter in prosthesis use and should be one of the main focus aspects of rehabilitation. The insights from this study are useful in rehabilitation practice because they allow therapists to specifically focus on certain parameters that may result in a higher level of skill for the prosthesis user.
\end{abstract}

Key words: amputation, force control, kinematics, motor control, myoelectric control, rehabilitation, skill level, task performance, transradial, upper-limb prosthesis, visual feedback.

\section{INTRODUCTION}

Clinical tests are often used in clinical practice to describe upper-limb prosthetic function (see Wright for an overview [1]). Such tests of specific tasks serve to assess performance, and aim to provide a general picture of the skill level of a prosthesis user. For example, the Trinity Amputation and Prosthesis Experience Scales (TAPES) assess satisfaction with the prosthesis and the influence of the prosthesis on performing activities of daily living (ADLs) [2]. However, the clinical level of description does not supply insight into the processes from which the level of skill originates: that is, the quality of movement execution and why the users perform in that manner, which is important information for rehabilitation practice. More insight into the skill level can be obtained when the score of a clinical test is related to a more kinematic level of description, which can provide

\footnotetext{
Abbreviations: $3 \mathrm{D}=$ three-dimensional, $\mathrm{ADL}=$ activity of daily living, $\mathrm{DGt}=$ direct grasping task, $\mathrm{HO}=$ high-resistance object, IGt $=$ indirect grasping task, $\mathrm{IoF}=$ Index of Functionality, $\mathrm{LO}=$ low-resistance object, $\mathrm{MO}=$ moderate-resistance object, $\mathrm{P}=$ participant, $\mathrm{PoR}=$ point of regard, $\mathrm{ROM}=$ range of motion, $\mathrm{S}=$ solid object, SHAP = Southampton Hand Assessment Procedure, TAPES $=$ Trinity Amputation and Prosthesis Experience Scales.

*Address all correspondence to Hanneke Bouwsema, MSc; Center for Human Movement Sciences, University of Groningen, PO Box 196, NL-9700 AD Groningen, the Netherlands; 31-50-363-2710; fax: 31-50-363-3150.

Email: H.Bouwsema@umcg.nl

http://dx.doi.org/10.1682/JRRD.2011.09.0179
} 
detailed information on the actual movement execution assessed by instruments like the TAPES. Moreover, by combining multiple levels of description, specific parameters in these movements that underlie skill level may be identified. This might be useful in rehabilitation because it allows therapists to specifically focus on the parameters in which an individual scores poorly, thereby enhancing the overall level of skill.

To maximize insight into the factors that contribute to the skill level of a prosthesis user, the current study employed a wide range of outcome measures, using a clinical test and several kinematic measures. As such, we follow and extend the suggestion put forth in several recent articles that evaluated measures of prosthesis functioning at the clinical level [1,3-4]. In these articles, it was concluded that several outcome measures should be combined to provide a complete picture of the functional ability of a prosthesis user instead of using only one outcome measure. For the clinical test, we used the Southampton Hand Assessment Procedure (SHAP) because of its objective character [5]. Although the SHAP needs more prosthesis-specific validation, this test is a promising, highly relevant measure [1] and recommended by the Upper Limb Prosthetic Outcome Measures group [6]. The SHAP is particularly suited for our purposes since it tests ADLs as well as tasks with abstract objects, which are the types of tasks mostly used in kinematic measures.

Kinematic measures have been used in several studies to report movement patterns of prosthesis use [7-13]. These studies measure end point kinematics or joint angles in goal-directed reaching and grasping tasks. Specific characteristics of prosthetic movements and deviations from sound movements are addressed, such as compensatory movements [7,9]. Changes in movement patterns are needed to compensate for the impaired ability of the prosthesis user (compare with Latash and Anson [14]). However, it is not known which deviations from sound movements are functional and which movements are excessive. In this study, we try to link compensation strategies with functional abilities, assessed with the clinical test. We assume that participants who score higher on the clinical test show the most functional compensation strategies. Even with these compensatory movements, we expect that a more skilled prosthesis user will approximate sound movement patterns more closely than a less skilled user.

Furthermore, two aspects that we also assume to define the skill level of a prosthesis user are control of the grip force of the prosthetic hand and the amount of visual attention needed to operate the prosthesis. It does not appear that these two aspects have been studied in prosthesis users previously. However, we propose that these two aspects will contribute to the understanding of prosthesis use; therefore, we try to fill this gap. Good grip force control is a prerequisite for skilled handling of the prosthesis in daily life, for example, when a prosthesis user holds a drink can or milk carton sufficiently firmly without crushing it in order to open it with their nondisabled hand. Because control of grip force is one of the most advanced aspects in the hierarchy of control training during the rehabilitation period [15], good grip force control requires a high level of dexterity. We hypothesize that better control of grip force while grasping nonrigid objects, (i.e., less deformation of the object during grasping) is related to greater user skills.

An additional aspect of user control that might reveal the skill level of a user is the amount of visual attention needed to guide the prosthetic hand through task execution. One of the aims in rehabilitation (and also in the development of new prostheses) is to decrease the amount of visual feedback that is needed [16-17]. Moreover, visual attention is one of the main items assessed in the Assessment of Capacity for Myoelectric Control [17]. In sound grasping, the eyes usually fixate on the object before the hand starts to move and stay focused on the object while executing the task, whereas the eyes are hardly ever fixated on the hands [18]. In learning to use a prosthesis, the user must visually monitor the hand because the prosthesis does not provide proprioceptive feedback about its aperture. We expect that better prosthesis skills will be accompanied by less visual support of the prosthesis and that gaze behavior will focus more on the object, as is the case in sound grasping.

To test our hypotheses, we assessed experienced prosthesis users with a clinical test (SHAP) and by applying two goal-directed fundamental tasks, a direct grasping task (DGt) with the prosthesis and an indirect grasping task (IGt) where the object is passed to the prosthesis with the nondisabled hand. In the fundamental tasks, we measured end point kinematics, joint angles, grip force control, and gaze behavior. Together with the SHAP, these measurements should provide a complete picture of prosthetic control and performance to meet the following objectives: (1) portray prosthetic handling at different levels of description, (2) relate the clinical results to the kinematic measures, and (3) identify specific 
parameters in these measures that characterize the factors contributing to the user's skill level.

\section{METHODS}

\section{Participants}

Six experienced users of a myoelectric transradial prosthesis (age [mean \pm standard deviation]: $36 \pm 18 \mathrm{yr}$; range 19-59 yr; see Table 1 for further characteristics) participated in the study. All six participants (P1-P6) used a passive wrist rotator; $\mathrm{P} 4$ also had a flexion wrist. The participants all reported good wearing comfort except P2, who felt the myoelectric prosthesis was heavy and therefore used a cosmetic prosthesis most of the time.

\section{Apparatus}

We used a Vicon motion analysis system (Vicon; Oxford, United Kingdom) (sampling frequency: $60 \mathrm{~Hz}$ ) with 8 cameras to record the positions of 15 reflective markers attached to the participant's head, trunk, and prosthetic arm in accordance with the upper-limb element of the Plug-in Gait model (Vicon). Furthermore, we attached one marker on the thumbnail and one on the index fingernail of the prosthetic hand and two markers on both sides of each of the objects used in the grasping tasks. We used a head-mounted eye-tracking system (model RK-826PCI, iScan Online, Inc; Dallas, Texas) synchronized with the Vicon motion analysis system to track the gaze behavior of the participant's left eye with a sample rate of $60 \mathrm{~Hz}$.

The SHAP consists of 26 tasks to evaluate the functionality of the hand: 12 abstract object tasks (6 lightweight and 6 heavyweight objects) and 14 ADLs. Time scores of each task provide an overall Index of Functionality (IoF) score (score of the hand function: a nondisabled hand scores between 95-100 and lower scores

Table 1.

Participant characteristics.

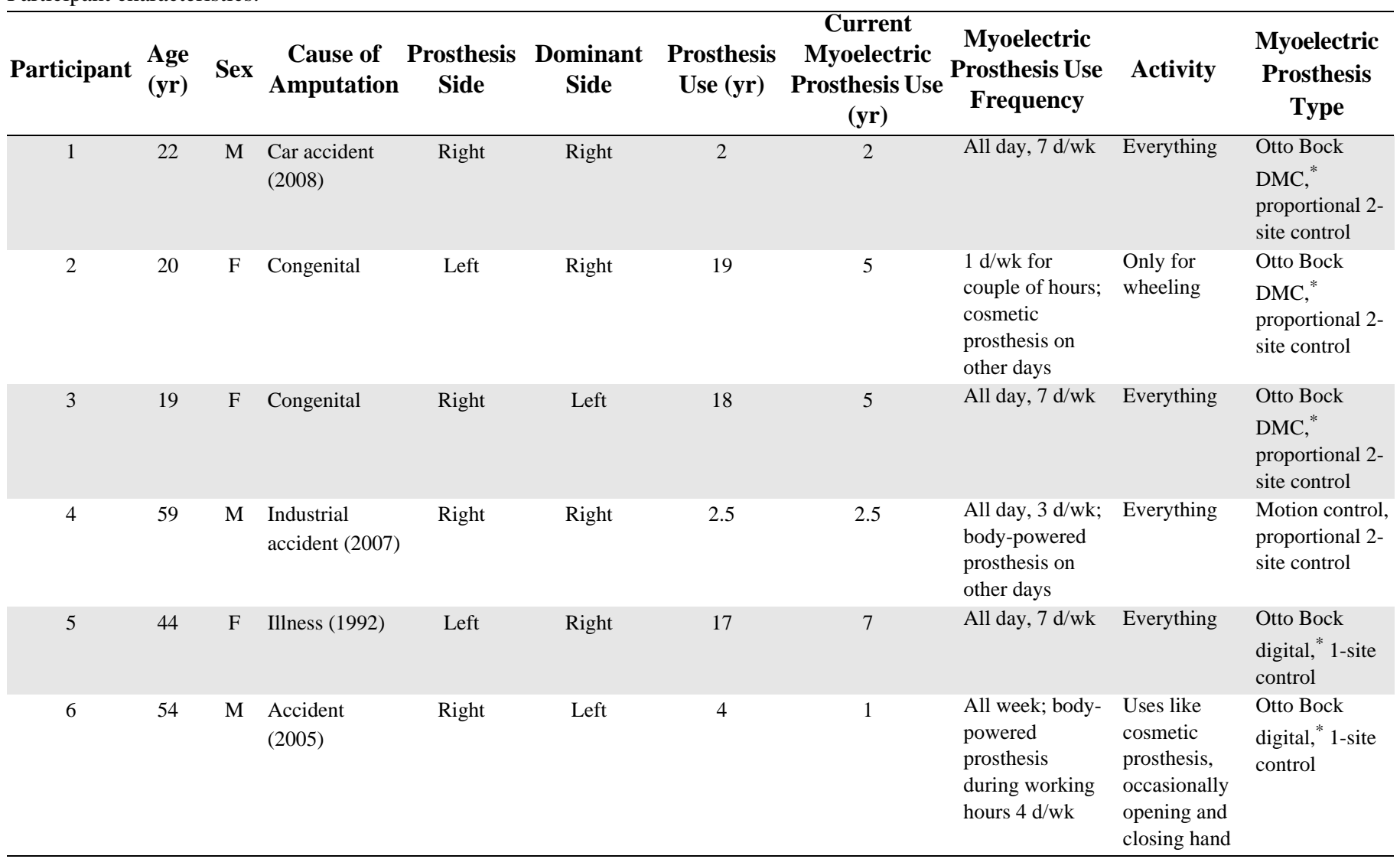

*ttobock; Vienna, Austria.

$\mathrm{F}=$ female, $\mathrm{M}=$ male. 
reflect decreased hand function) and a SHAP Functionality Profile with six prehensile pattern scores.

We used four objects in the grasping tasks, three compressible objects and one solid object (S) (all objects were $6 \times 3.5 \times 9 \mathrm{~cm}$ ) (Figure 1). The compressible objects consisted of two plates with a spring between. Each spring had a different resistance, requiring a different grip force before the object deformed-low-resistance object (LO) $(c=0.17 \mathrm{~N} / \mathrm{mm})$, moderate-resistance object (MO) $(c=0.57 \mathrm{~N} / \mathrm{mm})$, and high-resistance object (HO) $(c=5.31 \mathrm{~N} / \mathrm{mm})$. The compressible objects simulated objects used in daily life, such as a can or juice carton. A Velcro cover was mounted on top of each object. Participants were asked to remove the Velcro from front to back of the object. This was the manipulation part of the task for each object.

\section{Tasks}

\section{Southampton Hand Assessment Procedure}

The SHAP was conducted according to the standardized procedure.

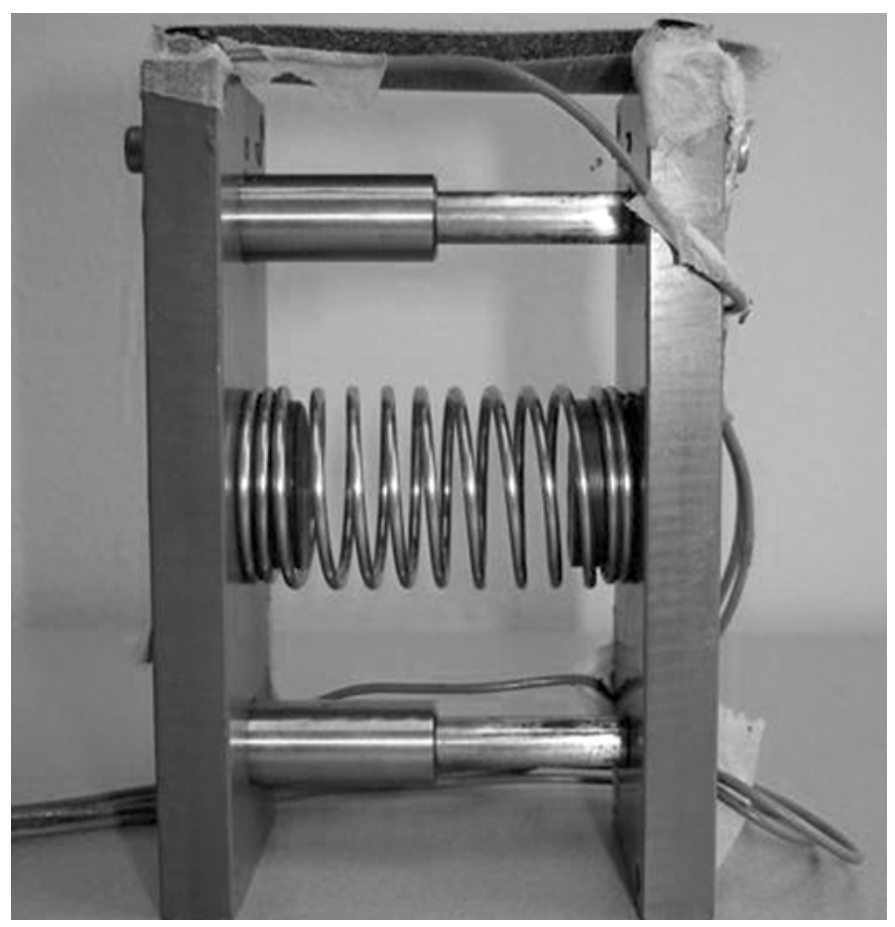

Figure 1.

Example of compressible object, consisting of two plates separated by spring with set resistance that defines how compressible object is.

\section{Direct Grasping Task}

The participants picked up an object from a table in front of them with their prosthetic hand, lifted it, manipulated it by removing the Velcro cover with the nondisabled hand, and placed it back to approximately the same position. The starting position of the prosthetic hand in the DGt was located $15 \mathrm{~cm}$ from the edge of the table, in line with the shoulder. The object was located $30 \mathrm{~cm}$ distal from the initial hand position in line with the shoulder.

\section{Indirect Grasping Task}

The object was initially situated in the nondisabled hand. The participants handed the object from their nondisabled hand to their prosthetic hand, manipulated it by removing the Velcro cover with the nondisabled hand, and placed it back on the table at the prosthetic hand starting position. The initial positions of the nondisabled hand and the prosthetic hand in the IGt were $25 \mathrm{~cm}$ from the edge of the table opposite each other in the frontal plane, with $30 \mathrm{~cm}$ distance between both hands. The center between the two hands aligned with the body midline.

\section{Procedure and Design}

Participants were seated comfortably at a table, with the table and chair adjusted in height for each individual. In all trials, participants began with their prosthetic hand closed. Following a "ready" signal given by the investigator at the start of each trial, the participants were free to initiate movement. Prior to each SHAP task, the investigator gave instructions on how to execute the task. Each task started and ended with the participant pressing a timer button. For the two grasping tasks, the participants were instructed to execute each of the tasks as rapidly and as accurately as possible while trying not to compress the objects. They were informed of the different object resistances. Each of the objects was grasped 5 times in a random order, resulting in a total of 40 grasping trials per participant.

\section{Data Analysis}

Because of the individual differences between the participants (prosthesis type, etc.), we analyzed the data for each participant separately. An IoF score and a Functionality Profile were calculated for the SHAP. The time scores of the SHAP were also transformed to z-scores, and mean z-scores were calculated for the lightweight abstract tasks, the heavyweight abstract tasks, and the 
ADL tasks to compare the performances on the different parts of the SHAP with each other and with other measures.

The onset and termination of the dependent variables in the fundamental tasks were determined with the method of Schot et al. that was implemented in customwritten MATLAB programs (MathWorks; Natick, Massachusetts) (Table 2) [19]. First, position and velocity for the markers of the hand, thumb, finger, and objects were computed. The time from reach onset until reach termination was the reach time; peak velocity was also determined. The grasp was defined by the three-dimensional
(3D) distance between the markers on the thumb and index finger, and maximum hand aperture was determined. The time between grasp onset and grasp termination defined grasp time. The period from the end of hand opening and the start of hand closing was defined as the plateau phase. Termination synchrony, which reflects the timing of the end of the reach and the grasp, was computed by dividing the time of grasp termination with the time of reach termination. A score of 1 stands for a simultaneous ending of the reach and grasp. When the

Table 2.

Cut-off thresholds of variables.

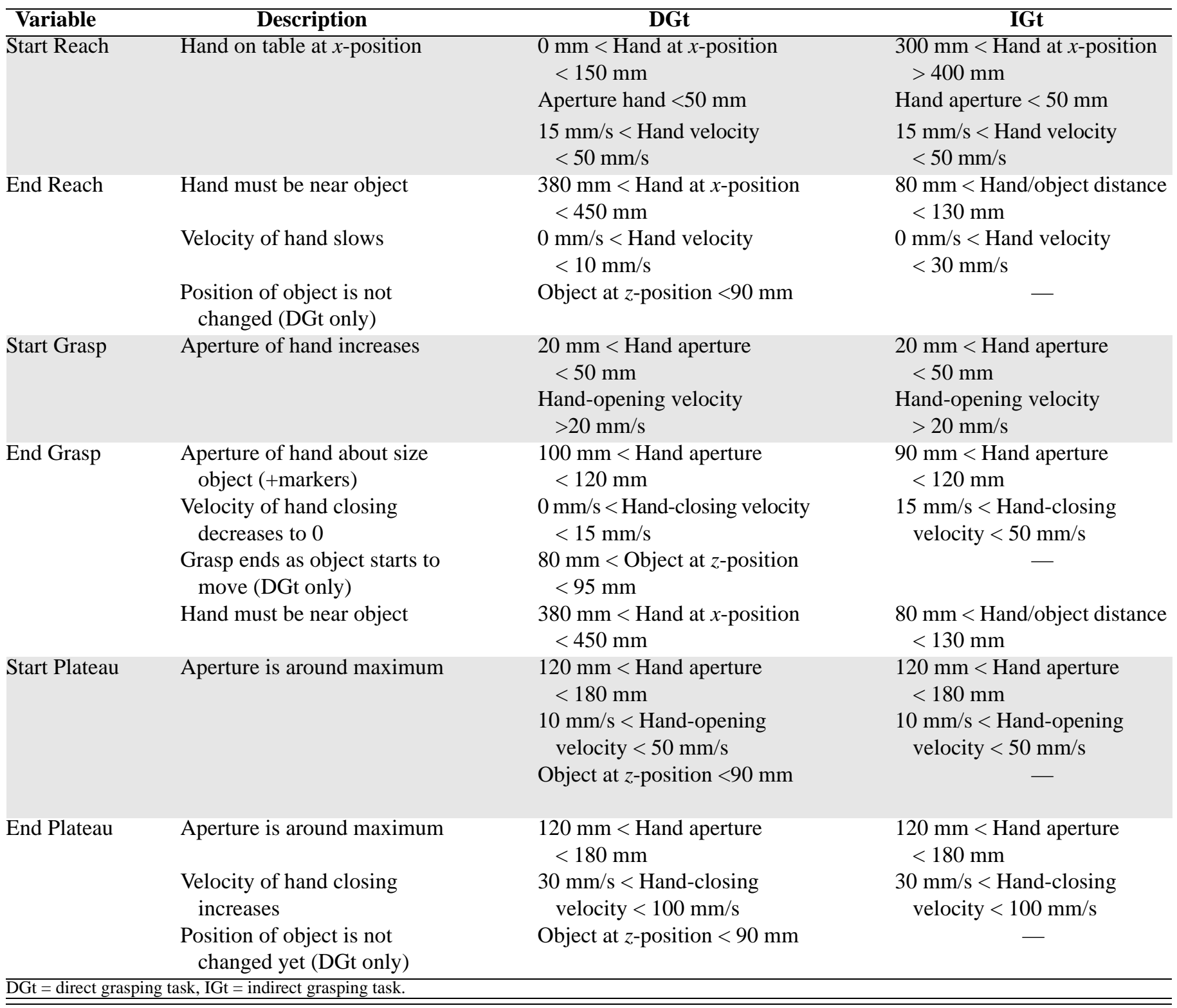


grasp ended later than the reach, scores exceeded 1, and when the grasp ended before the end of the reach, scores were lower than 1 . The higher the score, the later the end of the grasp compared with the end of the reach. For both tasks, the measures were computed relative to the position of the object - note that the object moved in the IGt. Compression of the object was calculated by computing the $3 \mathrm{D}$ distance between the two markers on opposite ends of the object.

We calculated joint angles with the Plug-in Gait model (Vicon): thorax flexion-extension, side-bending, and rotation; shoulder flexion-extension, abductionadduction, and rotation; and elbow flexion-extension. Range of motion (ROM) for each joint was calculated by subtracting the minimum value of the angle from the maximum value in each trial.

To examine the gaze behavior, the scene video produced by the head-mounted eye-tracking system with the point of regard (PoR) superimposed was scored frame by frame with Anvil 5.0 video-annotation software (German Research Centre for Artificial Intelligence [DFKI]; Saarbruecken, Germany). The image was divided in the following areas for the PoR scoring: object, hand, object and hand, other, and endpoint.

Two Kruskal-Wallis tests were executed on the dependent variables, one with grasp type (DGt and IGt) as grouping variable and one with object (LO, MO, HO, and S) as grouping variable, using SPSS 16.0 (IBM Corporation; Armonk, New York). The Bonferroni correction was used to correct for the multiple comparisons for each of the dependent variables within the two tests, resulting in a significance level of $0.05 / 8=0.006$. Spearman rho correlation was calculated between the mean $z$ score of the time scores of the SHAP, each of the end point kinematics, and gaze behavior. Trials were rejected when markers were obscured so that one or more of the variables could not be determined.

\section{RESULTS}

P1 was loaned a hand to perform the experiment because his prosthesis was broken at the time of the study. This hand was the same type the participant normally used, except that it did not have a flexion wrist. For P3, the corneal reflex needed to track the eye was not found by the iScan equipment, therefore there are no results on P3's gaze behavior. Because of problems with the prosthesis, the control mode of P5's prosthesis had to be changed just before the experiment, which resulted in subjectively poorer control of the prosthesis during the experiment because the participant had to get used to the new control system. Moreover, the markers on P5's fingers were occluded during the IGt; therefore, the end point kinematic data of the IGt is not presented for P5. P6 was cognitively challenged and sometimes had difficulties following the instructions. Because we wanted participants to reflect the population of prosthesis users, this participant was not removed.

\section{Southampton Hand Assessment Procedure}

Table 3 presents the $z$-scores and the scores of the IoF and six prehensile patterns. A negative $z$-score indicates better performance than the average score of the participants over all tasks, whereas a positive $z$-score indicates that the participant performed worse than the average score. The IoF score of all participants was far below the normal score of 95 to 100, with large differences between the participants. P1 scored the highest, whereas P5 and P6 scored much lower. This is also reflected in the $z$-scores, because the $z$-scores of P5 and P6 were mostly positive, whereas the scores of the other participants were mainly negative. Overall, the highest scores were obtained in the spherical grip, whereas the participants scored the lowest on the tip grip.

\section{End Point Kinematics and Object Compression}

Figure 2 shows a typical profile of the performance of two of the participants during a DGt trial. During the reach of the hand toward the object, the hand opened to a maximum aperture, plateaued, and started to close when the hand was near the object. When the object was picked up, two moments of compression could be determined. The first compression occurred directly at the moment when the object was picked up (indicated with arrow 1), and the second compression occurred when the Velcro strip was removed (indicated with arrow 2). The difference between the two participants can be clearly seen in the velocity of the hand during the reach, time needed to execute the task, length of the plateau in the aperture, and amount of compression of the object. Tables 4 and 5 present the significant effects of grasping task and object, respectively, on the dependent variables describing this behavior.

The different grasping tasks influenced variables of the movement of the hand toward the object (Table 4), whereas the effect of the objects was mainly reflected in 
Table 3.

Southampton Hand Assessment Procedure mean z-scores, Index of Functionality (IoF) scores, and scores of prehensile patterns.

\begin{tabular}{|c|c|c|c|c|c|c|}
\hline Task & P1 & $\mathbf{P 2}$ & P3 & $\mathbf{P 4}$ & P5 & P6 \\
\hline \multicolumn{7}{|l|}{ Abstract } \\
\hline Lightweight & -0.77 & -0.34 & -0.50 & -0.27 & 0.32 & - \\
\hline $\mathrm{ADL}$ & -0.63 & -0.51 & -0.25 & -0.37 & 0.64 & - \\
\hline IoF & 71 & 65 & 62 & 57 & 33 & 17 \\
\hline Spherical & 77 & 77 & 80 & 78 & 56 & 23 \\
\hline Power & 69 & 61 & 61 & 42 & 39 & 7 \\
\hline Lateral & 77 & 63 & 57 & 77 & 19 & 29 \\
\hline Tip & 59 & 33 & 32 & 42 & 12 & 8 \\
\hline Extension & 73 & 70 & 79 & 69 & 54 & 17 \\
\hline
\end{tabular}

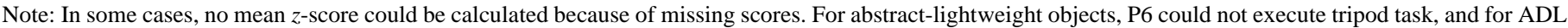
tasks, P6 was not able to execute food cutting, zipper, and screwdriver tasks.

$\mathrm{ADL}=$ activity of daily living, $\mathrm{P}=$ participant.

the dependent variables of the grasp and object manipulation (Tables 5-6). The DGt had longer reach times, longer plateau times, longer total grasp times, lower peak velocities, and larger apertures than the IGt (Table 4). No significant differences were found in the termination asynchrony and the compression of the object. However, the mean scores of each participant showed that the asynchrony was slightly higher for the IGt than the DGt. Moreover, the objects were less compressed during the IGt. P3 had the best performance because she picked up the object with almost no compression at all.

The different object resistances influenced several variables: an object with lower resistance had longer total grasp time, less synchronization of the end of the reach and the grasp, and more compression of the object (Tables 56). As expected, the effect of object resistance on the amount of compression of the object was significant in all participants. No significant effect was found in the plateau time; however, notice that the plateau time decreased with increasing object resistance.

Although no statistical comparisons were executed between the participants, P5 and P6 scored generally lower than the other participants, reflected by longer times, smaller peak velocities, and more compression of the objects.

\section{Joint Angles}

Table 7 displays the average ROM of the thorax, the shoulder, and the elbow for each participant. The overall movement pattern of the participants during the DGt was flexion of the trunk combined with some trunk side- bending toward the prosthesis side while rotating to the nonprosthesis side with the trunk. In order to pick up the object, the shoulder of the prosthetic arm moved in anteversion and internal rotation and the elbow was extended. There was much variation in the amount of shoulder abduction between the participants. P1 and P4 abducted their arm much more during the trial (an average of $50^{\circ}$ and $30^{\circ}$, respectively), while P5 and P6 limited their abduction to only $10^{\circ}$. The starting position of the arm differed largely between the participants: P1 and P3 started with an abduction of $40^{\circ}, \mathrm{P} 2$ and $\mathrm{P} 4$ started at $20^{\circ}$, and P5 and P6 only had about $10^{\circ}$ of abduction (Figure 3 ).

For the IGt, the movement pattern was slightly different, with almost no movement in the trunk (Table 7). The shoulder moved in anteversion and internal rotation during the trial, but less than during the DGt. Again, there was much variation in the amount of shoulder abduction, especially in the starting position of the arm. P1 started with a large shoulder abduction angle; P5 and P6 with almost no abduction; and P2, P3, and P4 with an angle between $20^{\circ}$ and $40^{\circ}$ (Figure 3). There was only a small degree of variation in the elbow angle during task execution for all participants.

\section{Eye Movement}

Overall, two types of gaze behaviors were found. P1, P4, and P5 first fixated on the object after the start of the trial and looked at the object most of the time during the trials. The average gaze behavior of P2 and P6 was for about two-thirds of the trials (distributed throughout the whole session) to look quickly at the object at the start of 

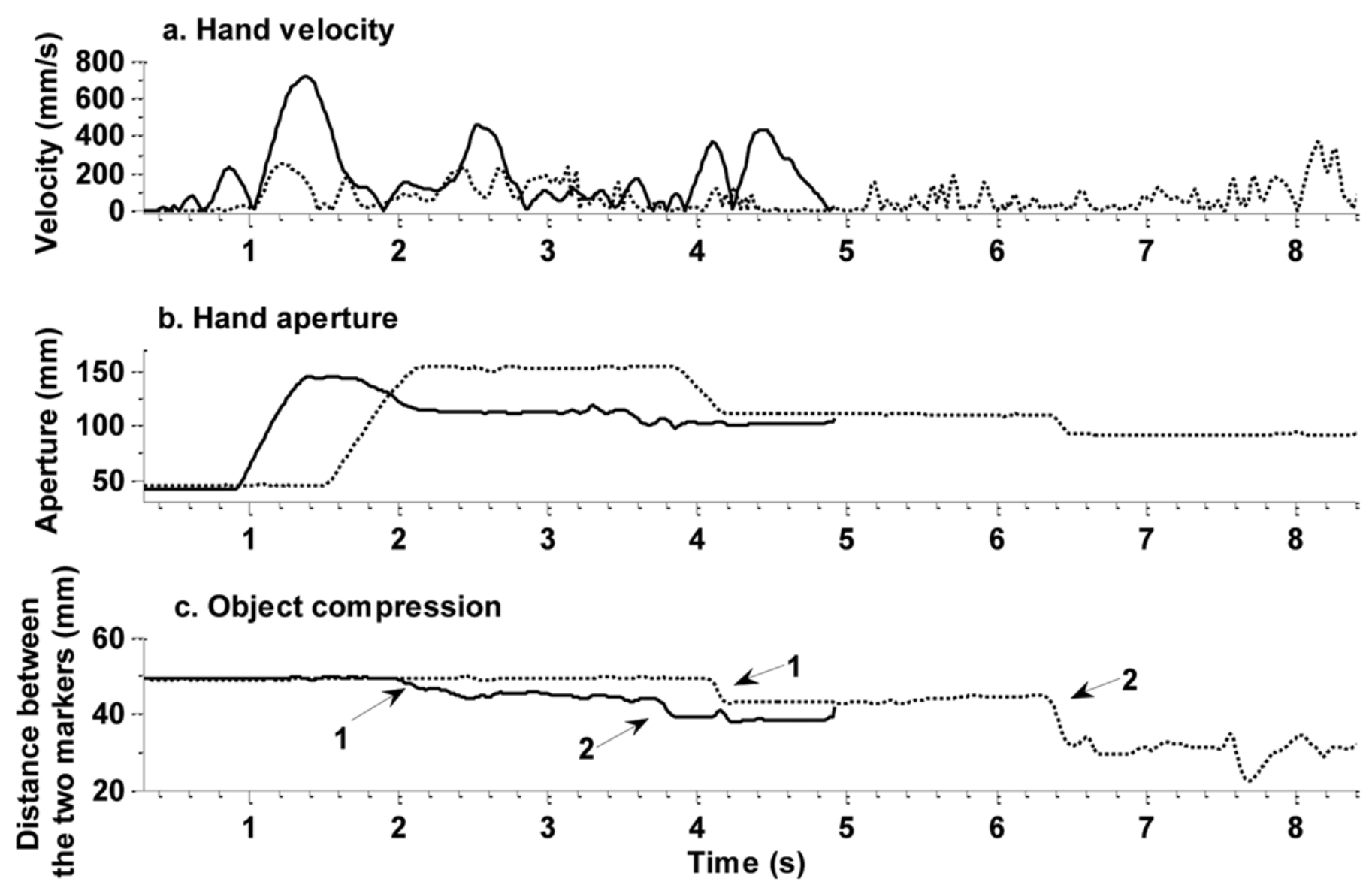

\section{Figure 2.}

Example of two participants who performed direct grasping task with compressible object. Solid line represents participant who scored highest on Southampton Hand Assessment Procedure (SHAP); dashed line represents participant who scored lowest on SHAP. 1 = Compression at time object is picked up, 2 = Compression when velcro strip is removed.

the trial, then at their prosthetic hand followed again by the fixation of the object again. For the other trials, P2 and P6 looked first at the hand before the object, especially during the DGt. During execution of a trial, the gazes of P2 and P6 switched repeatedly between the hand and the object. Figure 4 shows the difference in behavior: the total number of fixations per trial is larger for P2 and P6 than for the other participants (Figure 4(a)), while especially for P2 and a bit less for P6, the percentage of duration of fixation on the object is lower, whereas the percentage of duration of fixation in the hand is higher (Figure 4(b)). Note that P2 and P6 are the participants who did not use their myoelectric prosthesis much during the day. No differences in gaze behavior were found between the four different objects.

\section{Correlation Between Southampton Hand Assessment Procedure and Motion Analysis Results}

To determine whether the different measures are related, we performed correlation analyses between the measures. Also in these results, the differences in the performance of the participants can be seen, because P5 and P6 (who scored lower on the SHAP and had more deviations from sound behavior in the end point kinematics) are positioned at one side of the distribution, whereas P1 and P3 are located at the other end. The mean z-score of 
Table 4.

Mean \pm standard deviation (SD), 95 percent confidence interval (CI), and Kruskal-Wallis test (H) for significant effects of grasping tasks on dependent variables.

\begin{tabular}{|c|c|c|c|c|c|c|c|c|c|c|c|c|}
\hline \multirow{2}{*}{$\begin{array}{c}\text { Significant } \\
\text { Effect }\end{array}$} & \multicolumn{2}{|c|}{ P1 } & \multicolumn{2}{|c|}{$\mathbf{P 2}$} & \multicolumn{2}{|c|}{ P3 } & \multicolumn{2}{|c|}{ P4 } & \multicolumn{2}{|c|}{ P5 $^{*}$} & \multicolumn{2}{|c|}{ P6 } \\
\hline & DGt & IGt & DGt & IGt & DGt & IGt & DGt & IGt & DGt & IGt & DGt & IGt \\
\hline \multicolumn{13}{|l|}{ Reach Time (s) } \\
\hline Mean \pm SD & $\begin{array}{c}1.49 \pm \\
0.25\end{array}$ & $\begin{array}{c}1.06 \pm \\
0.26\end{array}$ & $\begin{array}{c}1.46 \pm \\
0.23\end{array}$ & $\begin{array}{c}1.31 \pm \\
0.48\end{array}$ & $\begin{array}{c}1.48 \pm \\
0.25\end{array}$ & $\begin{array}{c}0.96 \pm \\
0.19\end{array}$ & $\begin{array}{c}1.64 \pm \\
0.34\end{array}$ & $\begin{array}{c}1.09 \pm \\
0.95\end{array}$ & $\begin{array}{c}2.27 \pm \\
0.95\end{array}$ & - & $\begin{array}{c}3.18 \pm \\
1.92\end{array}$ & $\begin{array}{r}2.89 \pm \\
1.24\end{array}$ \\
\hline 95\% CI (LB) & 1.39 & 0.96 & 1.34 & 0.95 & 1.35 & 0.86 & 1.47 & 0.95 & 1.91 & - & 1.89 & 2.21 \\
\hline 95\% CI (UB) & 1.58 & 1.16 & 1.58 & 1.68 & 1.61 & 1.06 & 1.81 & 1.24 & 2.63 & - & 4.47 & 3.58 \\
\hline $\mathrm{H}$ & \multicolumn{2}{|c|}{24.96} & \multicolumn{2}{|c|}{1.22} & \multicolumn{2}{|c|}{21.22} & \multicolumn{2}{|c|}{16.56} & \multicolumn{2}{|c|}{ - } & \multicolumn{2}{|c|}{0.27} \\
\hline$p$-Value & \multicolumn{2}{|c|}{$0.00^{\dagger}$} & \multicolumn{2}{|c|}{0.27} & \multicolumn{2}{|c|}{$0.00^{\dagger}$} & \multicolumn{2}{|c|}{$0.00^{\dagger}$} & \multicolumn{2}{|c|}{ - } & \multicolumn{2}{|c|}{0.60} \\
\hline \multicolumn{13}{|c|}{ Peak Velocity (mm/s) } \\
\hline Mean \pm SD & $\begin{array}{c}664.39 \pm \\
81.47\end{array}$ & $\begin{array}{c}641.58 \pm \\
202.84\end{array}$ & $\begin{array}{c}337.51 \pm \\
66.76\end{array}$ & $\begin{array}{c}394.95 \pm \\
118.46\end{array}$ & $\begin{array}{r}369.22 \pm \\
61.38\end{array}$ & $\begin{array}{c}724.65 \pm \\
136.90\end{array}$ & $\begin{array}{c}477.15 \pm \\
134.82\end{array}$ & $\begin{array}{c}683.54 \pm \\
196.69\end{array}$ & $\begin{array}{r}247.98 \pm \\
58.44\end{array}$ & - & $\begin{array}{c}268.56 \pm \\
73.51\end{array}$ & $\begin{array}{r}562.22 \pm \\
195.63\end{array}$ \\
\hline 95\% CI (LB) & 633.40 & 561.34 & 301.93 & 303.90 & 337.66 & 656.57 & 407.83 & 569.97 & 225.75 & - & 219.17 & 453.89 \\
\hline 95\% CI (UB) & 895.38 & 721.82 & 373.08 & 486.01 & 400.78 & 792.73 & 546.47 & 797.10 & 270.21 & - & 319.95 & 670.55 \\
\hline $\mathrm{H}$ & & 07 & & & & & & & & & & \\
\hline$p$-Value & & 79 & & & & $0^{\dagger}$ & & $0^{\dagger}$ & & & & $0^{\dagger}$ \\
\hline Plateau Time (s) & & & & & & & & & & & & \\
\hline Mean \pm SD & $\begin{array}{c}0.40 \pm \\
0.23\end{array}$ & $\begin{array}{c}0.39 \pm \\
0.37\end{array}$ & $\begin{array}{c}0.91 \pm \\
0.37\end{array}$ & $\begin{array}{c}0.97 \pm \\
0.43\end{array}$ & $\begin{array}{c}0.51 \pm \\
0.29\end{array}$ & $\begin{array}{c}0.22 \pm \\
0.14\end{array}$ & $\begin{array}{c}0.96 \pm \\
0.53\end{array}$ & $\begin{array}{c}0.90 \pm \\
0.59\end{array}$ & $\begin{array}{c}1.10 \pm \\
0.61\end{array}$ & - & $\begin{array}{c}1.57 \pm \\
1.39\end{array}$ & $\begin{array}{r}1.84 \pm \\
1.13\end{array}$ \\
\hline 95\% CI (LB) & 0.32 & 0.24 & 0.71 & 0.64 & 0.36 & 0.15 & 0.69 & 0.56 & 0.86 & - & 0.63 & 1.22 \\
\hline 95\% CI (UB) & 0.49 & 0.53 & 1.11 & 1.30 & 0.66 & 0.29 & 1.24 & 1.24 & 1.33 & - & 2.50 & 2.47 \\
\hline $\mathrm{H}$ & & & & & & & & & & & & \\
\hline$p$-Value & & 15 & & & & $00^{\dagger}$ & & & & & & \\
\hline Total Grasp Time & (s) & & & & & & & & & & & \\
\hline Mean \pm SD & $\begin{array}{c}1.64 \pm \\
0.39\end{array}$ & $\begin{array}{c}1.30 \pm \\
0.56\end{array}$ & $\begin{array}{c}2.37 \pm \\
0.75\end{array}$ & $\begin{array}{r}2.79 \pm \\
0.93\end{array}$ & $\begin{array}{c}2.10 \pm \\
0.81\end{array}$ & $\begin{array}{c}1.43 \pm \\
0.47\end{array}$ & $\begin{array}{c}2.22 \pm \\
0.87\end{array}$ & $\begin{array}{c}2.46 \pm \\
1.01\end{array}$ & $\begin{array}{c}2.22 \pm \\
0.68\end{array}$ & - & $\begin{array}{r}5.21 \pm \\
4.14\end{array}$ & $\begin{array}{r}3.69 \pm \\
1.34\end{array}$ \\
\hline 95\% CI (LB) & 1.49 & 1.08 & 1.98 & 2.07 & 1.68 & 1.20 & 1.78 & 1.88 & 1.96 & - & 2.43 & 2.94 \\
\hline 95\% CI (UB) & 1.79 & 1.52 & 2.77 & 3.50 & 2.52 & 1.67 & 2.67 & 3.05 & 2.48 & - & 7.99 & 4.43 \\
\hline $\mathrm{H}$ & & & & & & & & & & & & \\
\hline$p$-Value & & $00^{\dagger}$ & & & & $0^{\dagger}$ & & & & & & \\
\hline Maximal Apertu & $\mathrm{e}(\mathrm{mm})$ & & & & & & & & & & & \\
\hline Mean \pm SD & $\begin{array}{r}144.61 \pm \\
1.51\end{array}$ & $\begin{array}{r}134.17 \pm \\
9.24\end{array}$ & $\begin{array}{r}142.71 \pm \\
5.37\end{array}$ & $\begin{array}{r}134.15 \pm \\
10.64\end{array}$ & $\begin{array}{r}126.82 \pm \\
7.15\end{array}$ & $\begin{array}{r}120.14 \pm \\
6.24\end{array}$ & $\begin{array}{r}132.68 \pm \\
0.97\end{array}$ & $\begin{array}{r}129.36 \pm \\
2.02\end{array}$ & $\begin{array}{r}150.57 \pm \\
0.74\end{array}$ & - & $\begin{array}{c}162.81 \pm \\
10.52\end{array}$ & $\begin{array}{c}163.39 \pm \\
10.95\end{array}$ \\
\hline 95\% CI (LB) & 144.04 & 130.52 & 139.84 & 125.97 & 123.14 & 117.04 & 132.18 & 128.19 & 150.29 & - & 155.74 & 157.33 \\
\hline 95\% CI (UB) & 145.19 & 137.82 & 145.57 & 142.33 & 130.50 & 123.25 & 133.17 & 130.53 & 150.60 & - & 169.87 & 169.45 \\
\hline $\mathrm{H}$ & & & & & & & & & & & & \\
\hline$p$-Value & & $00^{\dagger}$ & & & & & & $0^{\dagger}$ & & & & \\
\hline Termination Asy & ichrony & & & & & & & & & & & \\
\hline Mean \pm SD & $\begin{array}{c}1.20 \pm \\
0.11\end{array}$ & $\begin{array}{c}1.24 \pm \\
0.21\end{array}$ & $\begin{array}{c}1.72 \pm \\
0.32\end{array}$ & $\begin{array}{c}2.12 \pm \\
0.50\end{array}$ & $\begin{array}{c}1.48 \pm \\
0.42\end{array}$ & $\begin{array}{c}1.62 \pm \\
0.47\end{array}$ & $\begin{array}{c}1.33 \pm \\
0.28\end{array}$ & $\begin{array}{c}1.85 \pm \\
0.62\end{array}$ & $\begin{array}{c}1.44 \pm \\
0.39\end{array}$ & - & $\begin{array}{c}1.61 \pm \\
0.36\end{array}$ & $\begin{array}{c}1.68 \pm \\
0.56\end{array}$ \\
\hline 95\% CI (LB) & 1.16 & 1.15 & 1.55 & 1.74 & 1.26 & 1.38 & 1.19 & 1.50 & 1.29 & - & 1.37 & 1.37 \\
\hline 95\% CI (UB) & 1.25 & 1.32 & 1.89 & 2.50 & 1.70 & 1.85 & 1.47 & 2.21 & 1.59 & - & 1.85 & 2.00 \\
\hline $\mathrm{H}$ & & 15 & & & & & & & & & & \\
\hline$p$-Value & & 70 & & & & & & & & & & \\
\hline Compression Du & ing Grasp ( & $\mathrm{nm})$ & & & & & & & & & & \\
\hline Mean \pm SD & $\begin{array}{c}4.68 \pm \\
5.65\end{array}$ & $\begin{array}{c}1.60 \pm \\
2.90\end{array}$ & $\begin{array}{c}4.08 \pm \\
4.25\end{array}$ & $\begin{array}{r}2.51 \pm \\
1.34\end{array}$ & $\begin{array}{c}0.29 \pm \\
0.33\end{array}$ & $\begin{array}{c}0.67 \pm \\
0.76\end{array}$ & $\begin{array}{c}8.48 \pm \\
7.96\end{array}$ & $\begin{array}{c}2.70 \pm \\
3.62\end{array}$ & $\begin{array}{c}3.89 \pm \\
5.47\end{array}$ & - & $\begin{array}{c}7.08 \pm \\
7.88\end{array}$ & $\begin{array}{c}6.66 \pm \\
7.52\end{array}$ \\
\hline 95\% CI (LB) & 2.53 & 0.45 & 1.82 & 1.48 & 0.12 & 0.29 & 4.39 & 0.61 & 1.81 & - & 1.79 & 2.49 \\
\hline 95\% CI (UB) & 6.83 & 2.75 & 6.35 & 3.54 & 0.46 & 1.05 & 12.57 & 4.79 & 5.97 & - & 12.38 & 10.82 \\
\hline $\mathrm{H}$ & & & & & & & & & & & & \\
\hline$p$-Value & & 02 & & & & & & & & & & \\
\hline
\end{tabular}

Note: Degree of freedom = 1 for all dependent variables and participants.

Since there are no IGt outcome measures, Kruskal-Wallis test could not be performed for P5.

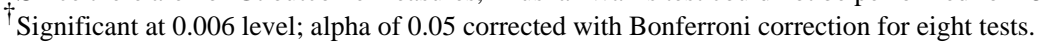

$\mathrm{DGt}=$ direct grasping task, IGt = indirect grasping task, LB = lower bound, $\mathrm{P}=$ participant, UB = upper bound . 
JRRD, Volume 49, Number 9, 2012

Table 5.

Mean \pm standard deviation (SD), 95 percent confidence interval (CI), and Kruskal-Wallis test (H) for effects of object on dependent variables.

\begin{tabular}{|c|c|c|c|c|c|c|c|c|c|c|c|c|}
\hline \multirow{2}{*}{ Variable } & \multicolumn{4}{|c|}{ P1 } & \multicolumn{4}{|c|}{ P2 } & \multicolumn{4}{|c|}{ P3 } \\
\hline & LO & MO & HO & $\mathrm{S}$ & LO & MO & HO & $\mathrm{S}$ & LO & MO & HO & $\mathrm{S}$ \\
\hline \multicolumn{13}{|l|}{ Plateau Time (s) } \\
\hline Mean \pm SD & $\begin{array}{r}0.51 \pm \\
0.37\end{array}$ & $\begin{array}{r}0.37 \pm \\
0.29\end{array}$ & $\begin{array}{r}0.38 \pm \\
0.29\end{array}$ & $\begin{array}{r}0.33 \pm \\
0.23\end{array}$ & $\begin{array}{r}1.01 \pm \\
0.40\end{array}$ & $\begin{array}{r}1.15 \pm \\
0.46\end{array}$ & $\begin{array}{r}0.91 \pm \\
0.24\end{array}$ & $\begin{array}{r}0.70 \pm \\
0.42\end{array}$ & $\begin{array}{r}0.38 \pm \\
0.14\end{array}$ & $\begin{array}{r}0.36 \pm \\
0.37\end{array}$ & $\begin{array}{r}0.36 \pm \\
0.27\end{array}$ & $\begin{array}{r}0.35 \pm \\
0.24\end{array}$ \\
\hline 95\% CI (LB) & 0.30 & 0.21 & 0.19 & 0.20 & 0.67 & 0.42 & 0.69 & 0.26 & 0.24 & 0.07 & 0.16 & 0.18 \\
\hline $95 \%$ CI (UB) & 0.73 & 0.53 & 0.57 & 0.45 & 1.34 & 1.89 & 1.13 & 1.14 & 0.53 & 0.65 & 0.55 & 0.52 \\
\hline $\mathrm{H}$ & \multicolumn{4}{|c|}{3.53} & \multicolumn{4}{|c|}{3.63} & \multicolumn{4}{|c|}{0.82} \\
\hline$p$-Value & \multicolumn{4}{|c|}{0.32} & \multicolumn{4}{|c|}{0.30} & \multicolumn{4}{|c|}{0.84} \\
\hline
\end{tabular}

Total Grasp Time (s)

\begin{tabular}{|c|c|c|c|c|c|c|c|c|c|c|c|c|}
\hline Mean \pm SD & $\begin{array}{r}1.96 \pm \\
0.43\end{array}$ & $\begin{array}{r}1.36 \pm \\
0.39\end{array}$ & $\begin{array}{r}1.36 \pm \\
0.47\end{array}$ & $\begin{array}{r}1.25 \pm \\
0.43\end{array}$ & $\begin{array}{r}3.09 \pm \\
0.77\end{array}$ & $\begin{array}{r}2.81 \pm \\
1.08\end{array}$ & $\begin{array}{r}2.29 \pm \\
0.54\end{array}$ & $\begin{array}{r}1.84 \pm \\
0.41\end{array}$ & $\begin{array}{r}2.59 \pm \\
1.19\end{array}$ & $\begin{array}{r}1.69 \pm \\
0.39\end{array}$ & $\begin{array}{r}1.53 \pm \\
0.57\end{array}$ & $\begin{array}{r}1.55 \pm \\
0.45\end{array}$ \\
\hline 95\% CI (LB) & 1.71 & 1.14 & 1.05 & 1.02 & 2.44 & 1.09 & 1.80 & 1.42 & 1.34 & 1.39 & 1.12 & 1.23 \\
\hline 95\% CI (UB) & 2.21 & 1.57 & 1.67 & 1.47 & 3.73 & 4.53 & 2.79 & 2.27 & 3.84 & 1.99 & 1.93 & 1.87 \\
\hline $\mathrm{H}$ & \multicolumn{4}{|c|}{16.06} & \multicolumn{4}{|c|}{8.19} & \multicolumn{4}{|c|}{7.60} \\
\hline$p$-Value & \multicolumn{4}{|c|}{$0.00^{*}$} & \multicolumn{4}{|c|}{0.04} & \multicolumn{4}{|c|}{0.06} \\
\hline
\end{tabular}

Termination Synchrony

\begin{tabular}{|c|c|c|c|c|c|c|c|c|c|c|c|c|}
\hline Mean \pm SD & $\begin{array}{r}1.40 \pm \\
0.21\end{array}$ & $\begin{array}{r}1.18 \pm \\
0.07\end{array}$ & $\begin{array}{r}1.16 \pm \\
0.10\end{array}$ & $\begin{array}{r}1.14 \pm \\
0.08\end{array}$ & $\begin{array}{r}2.26 \pm \\
0.48\end{array}$ & $\begin{array}{r}1.84 \pm \\
0.33\end{array}$ & $\begin{array}{r}1.72 \pm \\
0.22\end{array}$ & $\begin{array}{r}1.53 \pm \\
0.14\end{array}$ & $\begin{array}{r}2.04 \pm \\
0.54\end{array}$ & $\begin{array}{r}1.62 \pm \\
0.43\end{array}$ & $\begin{array}{r}1.36 \pm \\
0.37\end{array}$ & $\begin{array}{r}1.38 \pm \\
0.26\end{array}$ \\
\hline 95\% CI (LB) & 1.28 & 1.13 & 1.09 & 1.10 & 1.86 & 1.31 & 1.52 & 1.38 & 1.48 & 1.29 & 1.10 & 1.20 \\
\hline 95\% CI (UB) & 1.53 & 1.22 & 1.22 & 1.19 & 2.66 & 2.37 & 1.92 & 1.67 & 2.61 & 1.95 & 1.62 & 1.57 \\
\hline $\mathrm{H}$ & \multicolumn{4}{|c|}{13.92} & \multicolumn{4}{|c|}{10.98} & \multicolumn{4}{|c|}{8.59} \\
\hline$p$-Value & \multicolumn{4}{|c|}{$0.00^{*}$} & \multicolumn{4}{|c|}{0.01} & \multicolumn{4}{|c|}{0.04} \\
\hline
\end{tabular}

Compression at Grasp (mm)

\begin{tabular}{|c|c|c|c|c|c|c|c|c|c|c|c|}
\hline Mean \pm SD & $\begin{array}{r}3.29 \pm \\
3.63\end{array}$ & $\begin{array}{r}8.15 \pm \\
5.88\end{array}$ & $\begin{array}{r}0.97 \pm \\
0.69\end{array}$ & - & $\begin{array}{r}6.19 \pm \\
3.88\end{array}$ & $\begin{array}{r}5.55 \pm \\
3.15\end{array}$ & $\begin{array}{r}2.31 \pm \\
0.97\end{array}$ & - & $\begin{array}{r}1.16 \pm \\
0.88\end{array}$ & $\begin{array}{r}0.66 \pm \\
0.56\end{array}$ & $\begin{array}{r}0.41 \pm \\
0.36\end{array}$ \\
\hline 95\% CI (LB) & 1.19 & 4.90 & 0.50 & - & 2.95 & 0.53 & 1.41 & - & 0.23 & 0.23 & 0.16 \\
\hline 95\% CI (UB) & 5.39 & 11.4 & 1.44 & - & 9.44 & 10.6 & 3.21 & - & 2.08 & 1.09 & 0.67 \\
\hline $\mathrm{H}$ & \multicolumn{4}{|c|}{41.44} & \multicolumn{4}{|c|}{17.95} & \multicolumn{3}{|c|}{23.17} \\
\hline$p$-Value & \multicolumn{4}{|c|}{$0.00^{*}$} & \multicolumn{4}{|c|}{$0.00^{*}$} & \multicolumn{3}{|c|}{$0.00^{*}$} \\
\hline
\end{tabular}

Compression During Manipulation (mm)

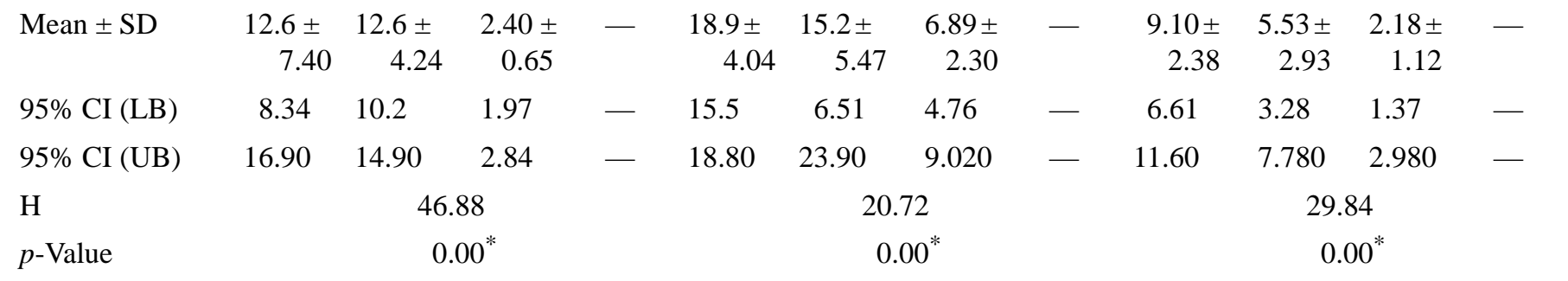

Note: Degree of freedom $=3$ for all dependent variables and participants.

${ }^{*}$ Significant at 0.006 level; alpha of 0.05 corrected with Bonferroni correction for eight tests.

$\mathrm{HO}=$ high-resistance object, $\mathrm{LB}=$ lower bound, $\mathrm{LO}=$ low-resistance object, $\mathrm{MO}=$ moderate-resistance object, $\mathrm{P}=$ participant, $\mathrm{S}=$ solid object, $\mathrm{UB}=$ upper bound . 
Table 6.

Mean \pm standard deviation (SD), 95 percent confidence interval (CI), and Kruskal-Wallis test (H) for effects of object on dependent variables.

\begin{tabular}{|c|c|c|c|c|c|c|c|c|c|c|c|c|}
\hline \multirow{2}{*}{ Variable } & \multicolumn{4}{|c|}{ P4 } & \multicolumn{4}{|c|}{ P5 } & \multicolumn{4}{|c|}{ P6 } \\
\hline & LO & MO & HO & $\mathbf{S}$ & LO & MO & HO & $\mathbf{S}$ & LO & MO & HO & $\mathbf{S}$ \\
\hline \multicolumn{13}{|l|}{ Plateau Time (s) } \\
\hline 95\% CI (LB) & 0.57 & 0.47 & 0.25 & 0.56 & 0.55 & 0.36 & 0.85 & 0.63 & 1.17 & 0.11 & 0.74 & 0.09 \\
\hline $\mathrm{H}$ & \multicolumn{4}{|c|}{2.07} & \multicolumn{4}{|c|}{4.73} & \multicolumn{4}{|c|}{3.8} \\
\hline$p$-Value & \multicolumn{4}{|c|}{0.56} & \multicolumn{4}{|c|}{0.19} & \multicolumn{4}{|c|}{0.28} \\
\hline
\end{tabular}

Total Grasp Time (s)

\begin{tabular}{|c|c|c|c|c|c|c|c|c|c|c|c|c|}
\hline Mean \pm SD & $\begin{array}{r}2.11 \pm \\
0.55\end{array}$ & $\begin{array}{r}2.79 \pm \\
1.10\end{array}$ & $\begin{array}{r}2.48 \pm \\
1.29\end{array}$ & $\begin{array}{r}1.99 \pm \\
0.50\end{array}$ & $\begin{array}{r}2.41 \pm \\
0.75\end{array}$ & $\begin{array}{r}2.51 \pm \\
0.83\end{array}$ & $\begin{array}{r}2.28 \pm \\
0.62\end{array}$ & $\begin{array}{r}1.77 \pm \\
0.35\end{array}$ & $\begin{array}{r}3.85 \pm \\
0.88\end{array}$ & $\begin{array}{r}3.40 \pm \\
0.56\end{array}$ & $\begin{array}{r}4.79 \pm \\
1.96\end{array}$ & $\begin{array}{r}4.82 \pm \\
4.98\end{array}$ \\
\hline 95\% CI (LB) & 1.69 & 1.78 & 1.40 & 1.53 & 1.62 & 1.75 & 1.76 & 1.47 & 3.03 & 2.50 & 2.98 & 0.66 \\
\hline $\mathrm{H}$ & \multicolumn{4}{|c|}{1.68} & \multicolumn{4}{|c|}{7.79} & \multicolumn{4}{|c|}{2.48} \\
\hline$p$-Value & \multicolumn{4}{|c|}{0.64} & \multicolumn{4}{|c|}{0.05} & \multicolumn{4}{|c|}{0.48} \\
\hline
\end{tabular}

Termination Synchrony

\begin{tabular}{|c|c|c|c|c|c|c|c|c|c|c|c|c|}
\hline Mean \pm SD & $\begin{array}{r}1.47 \pm \\
0.26\end{array}$ & $\begin{array}{r}1.97 \pm \\
0.85\end{array}$ & $\begin{array}{r}1.51 \pm \\
0.45\end{array}$ & $\begin{array}{r}1.35 \pm \\
0.26\end{array}$ & $\begin{array}{r}1.56 \pm \\
0.31\end{array}$ & $\begin{array}{r}1.61 \pm \\
0.61\end{array}$ & $\begin{array}{r}1.38 \pm \\
0.30\end{array}$ & $\begin{array}{r}1.25 \pm \\
0.22\end{array}$ & $\begin{array}{r}1.42 \pm \\
0.20\end{array}$ & $\begin{array}{r}1.84 \pm \\
0.76\end{array}$ & $\begin{array}{r}1.99 \pm \\
0.50\end{array}$ & $\begin{array}{r}1.47 \pm \\
0.32\end{array}$ \\
\hline 95\% CI (LB) & 1.27 & 1.19 & 1.14 & 1.11 & 1.23 & 1.04 & 1.13 & 1.06 & 1.24 & 0.63 & 1.52 & 1.21 \\
\hline $\mathrm{H}$ & \multicolumn{4}{|c|}{2.49} & \multicolumn{4}{|c|}{4.95} & \multicolumn{4}{|c|}{8.01} \\
\hline$p$-Value & \multicolumn{4}{|c|}{0.48} & \multicolumn{4}{|c|}{0.18} & \multicolumn{4}{|c|}{0.05} \\
\hline
\end{tabular}

Compression at Grasp (mm)

\begin{tabular}{|c|c|c|c|c|c|c|c|c|c|c|c|}
\hline Mean \pm SD & $\begin{array}{r}10.0 \pm \\
7.80\end{array}$ & $\begin{array}{r}8.67 \pm \\
7.43\end{array}$ & $\begin{array}{r}3.88 \pm \\
4.46\end{array}$ & - & $\begin{array}{r}9.18 \pm \\
6.08\end{array}$ & $\begin{array}{r}7.59 \pm \\
5.47\end{array}$ & $\begin{array}{r}0.59 \pm \\
0.30\end{array}$ & - & $\begin{array}{r}14.6 \pm \\
6.14\end{array}$ & $\begin{array}{r}12.2 \pm \\
6.80\end{array}$ & $\begin{array}{r}3.81 \pm \\
3.42\end{array}$ \\
\hline 95\% CI (LB) & 4.03 & 1.80 & 0.16 & - & 2.80 & 2.53 & 0.34 & - & 8.95 & 1.34 & 0.64 \\
\hline $\mathrm{H}$ & \multicolumn{4}{|c|}{18.71} & \multicolumn{4}{|c|}{22.76} & \multicolumn{3}{|c|}{21.24} \\
\hline p-Value & \multicolumn{4}{|c|}{$0.00^{*}$} & \multicolumn{4}{|c|}{$0.00^{*}$} & \multicolumn{3}{|c|}{$0.00^{*}$} \\
\hline
\end{tabular}

Compression During Manipulation (mm)

\begin{tabular}{|c|c|c|c|c|c|c|c|c|c|c|c|}
\hline Mean \pm SD & $\begin{array}{r}22.3 \pm \\
7.54\end{array}$ & $\begin{array}{r}28.6 \pm \\
4.02\end{array}$ & $\begin{array}{r}19.0 \pm \\
7.27\end{array}$ & - & $\begin{array}{r}19.2 \pm \\
5.83\end{array}$ & $\begin{array}{r}21.8 \pm \\
2.15\end{array}$ & $\begin{array}{r}15.5 \pm \\
6.71\end{array}$ & - & $\begin{array}{r}26.0 \pm \\
7.67\end{array}$ & $\begin{array}{r}21.7 \pm \\
3.42\end{array}$ & $\begin{array}{r}14.4 \pm \\
5.85\end{array}$ \\
\hline 95\% CI (LB) & 16.5 & 24.9 & 12.9 & - & 13.1 & 19.9 & 9.94 & - & 18.9 & 16.2 & 8.96 \\
\hline 95\% CI (UB) & 28.10 & 32.30 & 25.10 & - & 25.40 & 23.80 & 21.20 & - & 33.10 & 27.10 & 19.80 \\
\hline $\mathrm{H}$ & \multicolumn{4}{|c|}{22.11} & \multicolumn{4}{|c|}{19.15} & \multicolumn{3}{|c|}{21.67} \\
\hline$p$-Value & \multicolumn{4}{|c|}{$0.00^{*}$} & \multicolumn{4}{|c|}{$0.00^{*}$} & \multicolumn{3}{|c|}{$0.00^{*}$} \\
\hline
\end{tabular}

Note: Degree of freedom = 3 for all dependent variables and participants.

*Significant at 0.006 level; alpha of 0.05 corrected with Bonferroni correction for eight tests.

$\mathrm{HO}=$ high-resistance object, $\mathrm{LB}=$ lower bound, $\mathrm{LO}=$ low-resistance object, $\mathrm{MO}=$ moderate-resistance object, $\mathrm{P}=$ participant, $\mathrm{S}=$ solid object, $\mathrm{UB}=$ upper bound . 
Table 7.

Mean \pm standard deviation of range of motion (degrees) for shoulder, elbow, and thorax angles for direct and indirect grasping tasks.

\begin{tabular}{|c|c|c|c|c|c|c|c|}
\hline \multirow[b]{2}{*}{ Task } & \multicolumn{3}{|c|}{ Shoulder } & \multirow{2}{*}{$\begin{array}{c}\text { Elbow } \\
\text { Flexion- } \\
\text { Extension }\end{array}$} & \multicolumn{3}{|c|}{ Thorax } \\
\hline & $\begin{array}{c}\text { Flexion- } \\
\text { Extension }\end{array}$ & $\begin{array}{l}\text { Abduction- } \\
\text { Adduction }\end{array}$ & Rotation & & $\begin{array}{c}\text { Flexion- } \\
\text { Extension }\end{array}$ & Side Bending & Rotation \\
\hline \multicolumn{8}{|c|}{ Direct Grasping Task } \\
\hline $\mathrm{P} 2$ & $32.75 \pm 4.14$ & $21.33 \pm 3.18$ & $42.30 \pm 4.84$ & $32.47 \pm 3.87$ & $8.83 \pm 1.65$ & $8.91 \pm 1.97$ & $14.70 \pm 3.48$ \\
\hline P3 & $34.44 \pm 2.65$ & $17.96 \pm 8.12$ & $43.31 \pm 31.02$ & $42.55 \pm 1.45$ & $5.79 \pm 0.99$ & $6.20 \pm 1.79$ & $7.17 \pm 1.13$ \\
\hline P6 & $49.36 \pm 43.56$ & $39.85 \pm 49.43$ & $31.29 \pm 5.71$ & $34.41 \pm 3.34$ & $16.34 \pm 5.46$ & $12.56 \pm 6.21$ & $14.22 \pm 1.70$ \\
\hline \multicolumn{8}{|c|}{ Indirect Grasping Task } \\
\hline P1 & $16.14 \pm 4.22$ & $12.80 \pm 6.00$ & $23.56 \pm 7.19$ & $17.71 \pm 3.07$ & $3.90 \pm 1.89$ & $4.28 \pm 2.12$ & $3.03 \pm 1.25$ \\
\hline $\mathrm{P} 2$ & $13.77 \pm 2.14$ & $26.38 \pm 3.48$ & $26.43 \pm 5.33$ & $12.09 \pm 3.10$ & $4.29 \pm 1.30$ & $2.27 \pm 1.03$ & $5.10 \pm 1.96$ \\
\hline P3 & $14.81 \pm 5.22$ & $21.69 \pm 5.25$ & $25.94 \pm 4.07$ & $11.60 \pm 2.24$ & $3.12 \pm 0.94$ & $3.26 \pm 1.44$ & $2.70 \pm 1.06$ \\
\hline
\end{tabular}

the heavyweight abstract tasks of the SHAP correlated significantly with the reach time of the DGt and IGt $\left(r_{\mathrm{s}}=\right.$ $0.83, p=0.04$ ); the better the score (i.e., the more negative the $z$-score), the shorter the reach time. A more negative $z$-score of the heavyweight abstract tasks was significantly correlated with a higher peak velocity $\left(r_{\mathrm{s}}=\right.$ $-0.83, p=0.04)$. Importantly, a shorter plateau time was related to a more negative $z$-score of the lightweight abstract tasks $\left(r_{\mathrm{s}}=0.90, p=0.04\right)$. Note that the occurrence of the plateau in the grasping profile is a distinguishing characteristic of prosthetic use. There were no other significant correlations.

\section{DISCUSSION}

The aims of this study were to portray prosthetic functioning at different levels of description, relate the results of the clinical outcome measures with the results of the kinematic measures, and identify specific parameters that characterize the skill level of a user. We assumed that a more skilled prosthesis user would score higher on the SHAP, and that better skills would be reflected in better functional compensation strategies, better grip force control of the hand, and more approximation to sound movement patterns and sound gaze behavior. Our findings show that, overall, the results confirmed our hypotheses.
Although the scores on the SHAP were far below the normal score with a nondisabled hand, the scores provided a good basis for the level of skill of the prosthesis user. The test reflected differences between the functional abilities of the participants as was also found previously [20]. As in Kyberd et al., our participants scored the lowest on the tip grip, despite the fact that their hand wasby default—set in tip grip [20]. This was only logical, however, since the most difficult tasks were included in the tip grip score, such as picking up coins, the zipping task, and the screwdriver task. The functional ability of each participant scored by the SHAP was confirmed by the kinematic measures. As expected, the higher the score on the SHAP (thus the closer to a normal score), the more the movement and gaze patterns of the prosthesis user approximated those of nondisabled persons.

The participants who scored higher on the SHAP showed movement patterns in the end point kinematics that deviated less from sound movement patterns (see Bouwsema et al. [8]), with shorter movement times, shorter plateau times, and less object compression. Overall, similar movement profiles were found as reported in earlier studies with prosthesis users, with the characteristic plateau phase bridging hand opening with hand closing [8,12-13]. Indirect grasping seemed to be easier to perform than direct grasping based on the shorter times, higher peak velocities, smaller maximum hand apertures (the larger apertures in the DGt were probably to increase 

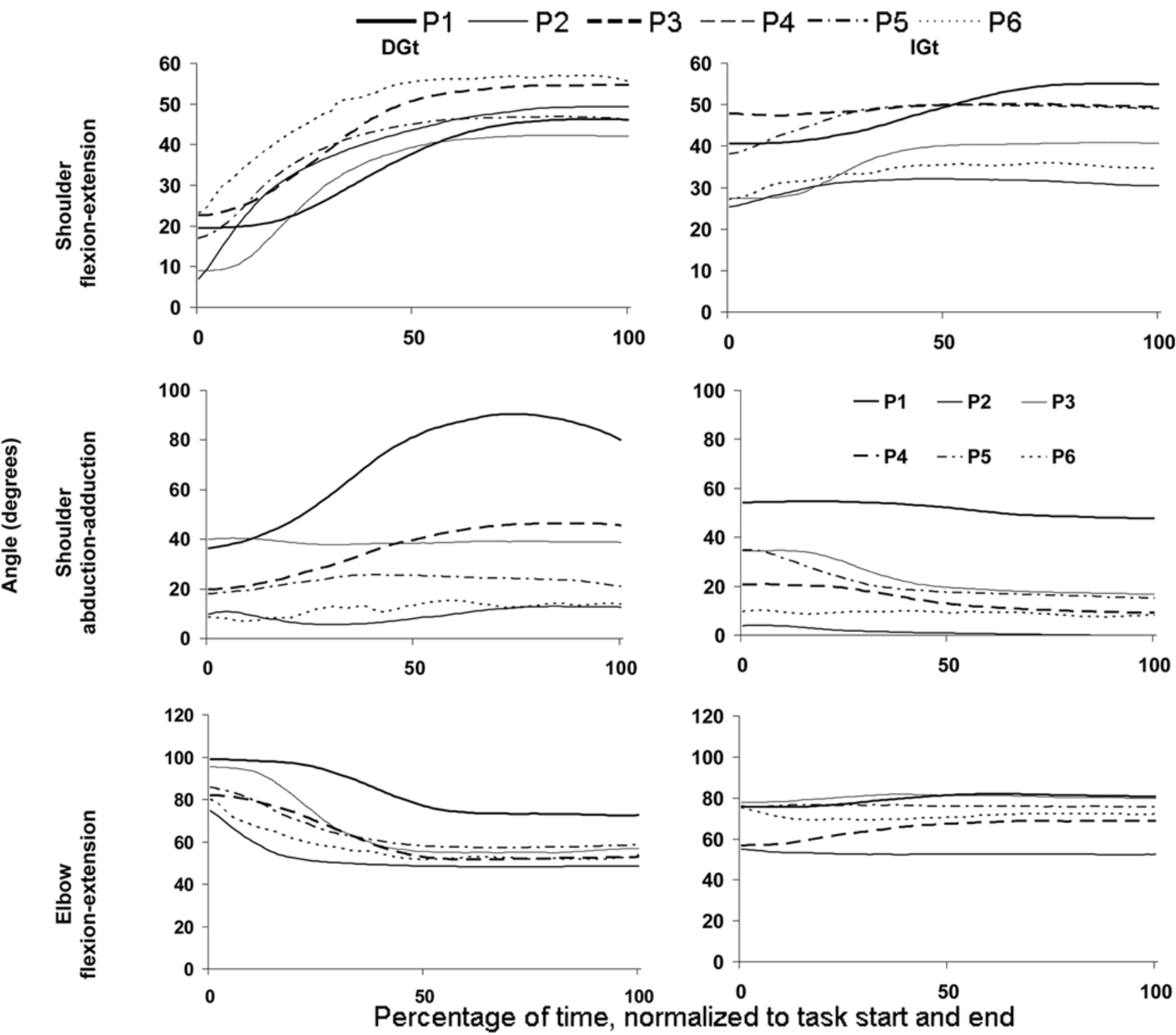

Figure 3.

Average joint angle of each participant $(P)$ for elbow flexion-extension, shoulder flexion-extension, and shoulder abduction-adduction plotted against normalized time for both direct and indirect grasping tasks.

the tolerance for errors), and less compression of the objects during that task. These findings are in agreement with the fact that indirect grasping is more often performed with a prosthesis in daily life than direct grasping [21]. Moreover, in the IGt the nondisabled hand contributes to the performance as well, whereas the DGt is executed with the prosthetic hand alone. The large effect of the objects for all participants revealed that they were all able to adjust the grip force to the characteristics of the object; although participants who scored higher on the SHAP compressed the objects less intensely or, in other words, they showed a better grip force control.

Overall, the movement patterns in the joint angles were rather similar for all participants, except for the variation in the amount of shoulder abduction. We interpreted that more shoulder abduction was used to compensate for the lack of wrist movement in the prosthesis. Although P4 had a flexion wrist, his movement patterns were not 
(a)
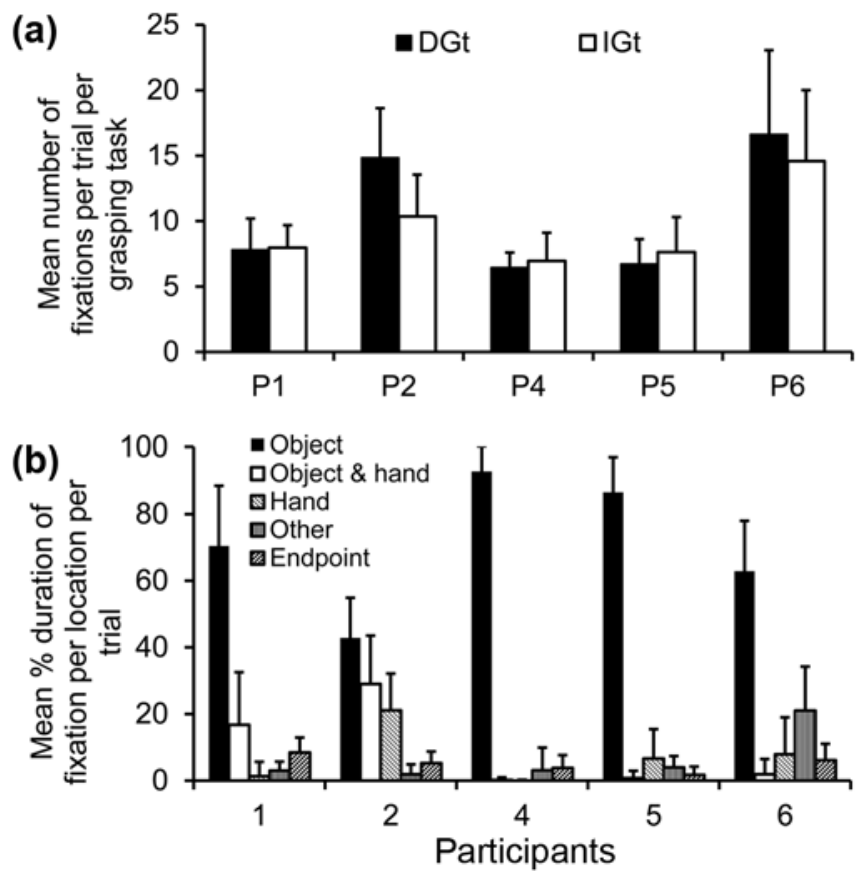

Figure 4.

(a) Mean number of eye fixations per trial for direct grasping task (DGt) and indirect grasping task (IGt). (b) Mean percentage of duration of eye fixations per location in trial. $\mathrm{P}=$ participant.

different from the other participants who did not have this additional function. We assumed that the betterperforming participants would show the most functional compensation strategies and that movement patterns of higher-skilled participants would more resemble nondisabled movement patterns. However, in this regard results were different than expected. P1, who overall performed best out of the six participants, had the largest abduction angles in the shoulder, while P5 and P6, the two participants with the lowest performance, showed the smallest abduction angles. This implies that participants with the highest functional scores may also show movement behaviors that largely deviate from nondisabled behavior (i.e., extensive compensatory behavior), which is contrary to what we anticipated. Usually, the aim of rehabilitation is to reduce compensatory movements as much as possible $[7,9]$ and to bring movement patterns back as close as possible to those of nondisabled movement patterns [14] to reduce load and strain on joints as well as to avoid injury and overuse. However, an alternative view on compensatory movements put forth by Latash and Anson is that these movements reflect a solution given the motor characteristics of the patient and the task [14].
In this view, training to reduce compensatory movements as much as possible might not always be adequate for daily life, and we see signs of this in our data. These results show that one can be effective with an obvious compensation strategy. Therefore, it might be that training should rather be directed toward the most functional movements for the type of task, taking into account the residual functions and characteristics of the user in order to determine the acceptable and necessary extent of compensatory movements that are adequate in order to train that user to be as skilled as possible.

Differences between the participants were also seen in the gaze behavior. This part of behavior has, to our knowledge, never been reported previously in prosthesis use. The lack of proprioceptive feedback means that prosthesis users presumably have to rely on vision, so gaze behavior would seem to be an obvious informative measure for the quality of prosthesis control. Overall, two types of gaze behavior were observed in this study. The first type was to look continuously at the object during execution of the task, which is a gaze strategy that is generally observed in the handling of objects in ADLs [18]. The second type of behavior was to switch the gaze back and forth between the object and the prosthetic hand. The latter monitoring of the hand indicated that the participant needs to visually guide the prosthetic hand. It was expected that users who were less skilled in handling the prosthesis would show more monitoring of the hand during action performance, as was the case for P6. However, P2 also showed this behavior but was relatively highly skilled in handling the prosthesis. Since P2 and P6 were the two participants who did not use the myoelectric prosthesis much during the week, gaze behavior might be related more to the duration of use rather than to the functional abilities. It is worth noting that, despite the lack of proprioception, the gaze in all participants was directed toward the object for most of the time. However, it is important to note that all participants were experienced prosthesis users. It would be interesting to examine gaze behavior throughout the rehabilitation process. It is expected that the amount of visual attention to the prosthetic hand would be higher at the start and diminish throughout the rehabilitation process. This measure would be an indication of how the skills of the user develop over time.

Overall, the results of the different measurements were in agreement with each other and also complemented each other because each of the more fundamental 
measures provided deeper insight into the performance of the participant on the SHAP and, thus, into skills of the participants. However, an important question arises: when is a prosthesis user a "skilled user" and how should skill level be defined? Bernstein (one of the pioneers in the field of motor control) had a very clear vision and definition of skill [22] (see also Latash and Latash [23]). In this final part of the discussion, his ideas were used to meet the third objective of this study: identify specific parameters that define skill of prosthesis users. Bernstein defined skill, or dexterity, as "the ability to find a motor solution for any situation, that is, to adequately solve any emerging motor problem correctly (i.e., adequately and accurately), quickly (with respect to both decision making and achieving a correct result), rationally (i.e., expediently and economically), and resourcefully (i.e., quickwittedly and initiatively)” [22, p. 228]. Bernstein emphasized that people differ in the amount of dexterity they develop; one person can be more dexterous than another. More importantly, dexterity can be trained; however, the amount of dexterity that can be trained is different for each person.

Furthermore, Bernstein argued that dexterity is not in the movements themselves but rather in the interaction of the motor processes and perceptual processes with the environment. The more complex and unpredictable the environment and the tasks and the better a person performs in that specific situation, the higher the person's dexterity (compare with Beek [24]). These insights are applicable to the performance of the participants in the present study. The SHAP is a functional test with very complex tasks, especially in the ADL part of the test. Moreover, picking up a compressible object is complex, because the participant not only has to pick up the object but at the same time has to try not to compress the object. On top of that, participants also had to manipulate the object by removing the Velcro while trying not to squeeze the object. This study showed that some prosthesis users differed substantially in performance on both the SHAP and the grasping tasks. Therefore, we concluded that the better performers are more dexterous, and therefore more skilled, since they were more capable of interacting with the changing and demanding environment. In light of Bernstein's definition of dexterity, we found that participants with a higher performance executed the tasks (1) more correctly, because they were able to finish all SHAP tasks and compressed the deformable objects less; (2) more quickly; (3) more rationally, with adequate ROMs and ranges of visual guidance; and (4) more resourcefully, which was especially noticed in the SHAP where we could see that the quicker a person knew how to perform a task, the better the person's performance.

Moreover, Bernstein argued that several movement characteristics predict performance in a set of movements. In this study, we identified certain parameters that are characteristics of skills in prosthesis use by means of the correlations between the different measures. The one parameter that was seen throughout the whole performance was time: the time needed to execute the tasks in both the clinical test and in the various dependent variables of the fundamental measures. This time is what Bernstein defined as "quickness," which features importantly in his definition of dexterity; hence, in rehabilitation it is worthwhile to spend time on quickness because it can lead to substantial improvement [22]. Therefore, we suggest particularly focusing on the time aspect of movement execution during training to increase the skill level of a patient. An important parameter determining the time of a grasping movement with a prosthesis is the plateau phase in the grasping profile (see also Bouwsema et al. [8]), which reflects the coupling of hand opening and closing [25]. This parameter showed the highest correlation with the SHAP scores. Therefore, we argue that prosthesis training should focus specifically on reducing the duration of the plateau phase. Training coordination of hand opening and closing, which will reduce this plateau phase, would not only improve control of the different signals to open and close the hand, but moreover, movements will look more natural. The quicker a prosthesis user is with the prosthesis, the better and therefore more skilled his or her performance will be. As a result, the prosthesis probably will be used more frequently and with more satisfaction in daily life.

\section{CONCLUSIONS}

In this study, we measured prosthesis use on different levels of description using clinical and kinematic measures. This study followed and extended the suggestion to combine several outcome measures, as discussed in the "Introduction," by not only measuring on a clinical, functional level, but also on more kinematic levels. The results provided a wide range of information. The clinical test (SHAP) was a good measure of skill level of the 
prosthesis user, whereas the fundamental measures provided deeper insight into the performance and skill level of the prosthesis users. Participants who scored higher on the SHAP showed less deviation in end point kinematic profiles from nondisabled movement patterns, with, among other factors, shorter movement times, higher peak velocities, and shorter plateau times in the aperture. Moreover, they showed better grip force control and less visual attention to the hand. The results show that time is a key parameter in prosthesis use and should be one of the main aspects of focus in rehabilitation. The insights provided by this study are useful in rehabilitation, because they allow therapists to specifically focus on certain parameters such as plateau time or visual control, which will hopefully result in the highest level of skill that can be achieved for that prosthesis user.

\section{ACKNOWLEDGMENTS}

\section{Author Contributions: \\ Study concept and design: H. Bouwsema, C. K. van der Sluis, R. M. Bongers. \\ Acquisition of data: H. Bouwsema, P. J. Kyberd, W. Hill. Analysis and interpretation of data: H. Bouwsema, R. M. Bongers. Drafting of manuscript: H. Bouwsema. \\ Critical revision of manuscript for important intellectual content: \\ C. K. van der Sluis, R. M. Bongers, W. Hill, P. J. Kyberd. \\ Obtained funding: H. Bouwsema, C. K. van der Sluis, R. M. Bongers, W. Hill, P. J. Kyberd. \\ Study supervision: P. J. Kyberd, C. K. van der Sluis, R. M. Bongers.}

Financial Disclosures: The research was performed while Ms. Bouwsema was financially supported by Otto Bock Healthcare GmbH, Vienna, Austria.

Funding/Support: This material is based on work supported by the ISPO Nederland and the Anna Fonds Netherlands Orthopedic Research and Education Foundation (grant br2010/13).

Additional Contributions: The authors would like to thank John Landry for help with running the experiment.

Institutional Review: This study was approved by the Institutional Research Ethics Board of the University of New Brunswick (REB application 2010-099). An informed consent was signed by each participant before the start of the experiment.

Participant Follow-up: The authors plan to inform participants of the publication of this study.

\section{REFERENCES}

1. Wright V. Prosthetic outcome measures for use with upper limb amputees: A systematic review of the peer-reviewed literature, 1970 to 2009. J Prosthet Orthot. 2009;21(Suppl
9):P3-P63.

http://dx.doi.org/10.1097/JPO.0b013e3181ae9637

2. Desmond DM, MacLachlan M. Factor structure of the Trinity Amputation and Prosthesis Experience Scales (TAPES) with individuals with acquired upper limb amputations. Am J Phys Med Rehabil. 2005;84(7):506-13. [PMID:15973087]

http://dx.doi.org/10.1097/01.phm.0000166885.16180.63

3. Hill W, Kyberd PJ, Hermansson L, Hubbard S, Stavdahl Ø, Swanson S. Upper limb prosthetic outcome measures (ULPOM): A working group and their findings. J Prosthet Orthot. 2009;21(Suppl 9):P69-P82.

http://dx.doi.org/10.1097/JPO.0b013e3181ae970b

4. Lindner HY, Nätterlund BS, Hermansson LM. Upper limb prosthetic outcome measures: review and content comparison based on International Classification of Functioning, Disability and Health. Prosthet Orthot Int. 2010;34(2):109-28. [PMID:20470058] http://dx.doi.org/10.3109/03093641003776976

5. Light CM, Chappell PH, Kyberd PJ. Establishing a standardized clinical assessment tool of pathologic and prosthetic hand function: normative data, reliability, and validity. Arch Phys Med Rehabil. 2002;83(6):776-83.

[PMID:12048655]

http://dx.doi.org/10.1053/apmr.2002.32737

6. Miller LA, Swanson S. Summary and recommendations of the academy's state of the science conference on upper limb prosthetic outcome measures. J Prosthet Orthot. 2009; 21(Suppl 9):P83-P89.

http://dx.doi.org/10.1097/JPO.0b013e3181ae974d

7. Bertels T, Schmalz T, Ludwigs E. Objectifying the functional advantages of prosthetic wrist flexion. J Prosthet Orthot. 2009;21:74-78.

http://dx.doi.org/10.1097/JPO.0b013e3181a10f46

8. Bouwsema H, van der Sluis CK, Bongers RM. Movement characteristics of upper extremity prostheses during basic goal-directed tasks. Clin Biomech (Bristol, Avon). 2010; 25(6):523-29. [PMID:20362374] http://dx.doi.org/10.1016/j.clinbiomech.2010.02.011

9. Carey SL, Jason Highsmith M, Maitland ME, Dubey RV. Compensatory movements of transradial prosthesis users during common tasks. Clin Biomech (Bristol, Avon). 2008;23(9):1128-35. [PMID:18675497]

http://dx.doi.org/10.1016/j.clinbiomech.2008.05.008

10. Carey SL, Dubey RV, Bauer GS, Highsmith MJ. Kinematic comparison of myoelectric and body powered prostheses while performing common activities. Prosthet Orthot Int. 2009;33(2):179-86. [PMID:19367522] http://dx.doi.org/10.1080/03093640802613229

11. Dromerick AW, Schabowsky CN, Holley RJ, Monroe B, Markotic A, Lum PS. Effect of training on upper-extremity prosthetic performance and motor learning: a single-case 
study. Arch Phys Med Rehabil. 2008;89(6):1199-1204. [PMID:18503820]

http://dx.doi.org/10.1016/j.apmr.2007.09.058

12. Fraser C, Wing AW. A case study of reaching by a user of a manually-operated artificial hand. Prosthet Orthot Int. 1981;5(3):151-56. [PMID:7329778]

13. Wing AM, Fraser C. The contribution of the thumb to reaching movements. Q J Exp Psychol A. 1983;35(Pt 2):297-309. [PMID:6571312] http://dx.doi.org/10.1080/14640748308402135

14. Latash ML, Anson JG. What are "normal movements" in atypical populations? Behav Brain Sci. 1996;19:55-106. http://dx.doi.org/10.1017/S0140525X00041467

15. Smurr LM, Gulick K, Yancosek K, Ganz O. Managing the upper extremity amputee: a protocol for success. J Hand Ther. 2008;21(2):160-76. [PMID:18436138] http://dx.doi.org/10.1197/j.jht.2007.09.006

16. Blank A, Okamura AM, Kuchenbecker KJ. Identifying the role of proprioception in upper-limb prosthesis control: Studies on targeted motion. ACM Trans Appl Percept. 2010;7(3):1. http://dx.doi.org/10.1145/1773965.1773966

17. Hermansson LM, Fisher AG, Bernspång B, Eliasson A-C. Assessment of capacity for myoelectric control: a new Rasch-built measure of prosthetic hand control. J Rehabil Med. 2005;37(3):166-71. [PMID:16040474]

18. Land MF, Hayhoe M. In what ways do eye movements contribute to everyday activities? Vision Res. 2001;41(2526):3559-65. [PMID:11718795] http://dx.doi.org/10.1016/S0042-6989(01)00102-X

19. Schot WD, Brenner E, Smeets JB. Robust movement segmentation by combining multiple sources of information. J Neurosci Methods. 2010;187(2):147-55. [PMID:20096305] http://dx.doi.org/10.1016/j.jneumeth.2010.01.004

20. Kyberd PJ, Murgia A, Gasson M, Tjerks T, Metcalf C, Chappell PH, Warwick K, Lawson SE, Barnhill T. Case studies to demonstrate the range of applications of the Southampton Hand Assessment Procedure. Br J Occup Ther. 2009;72:212-18.
21. van Lunteren A, van Lunteren-Gerritsen GH, Stassen HG, Zuithoff MJ. A field evaluation of arm prostheses for unilateral amputees. Prosthet Orthot Int. 1983;7(3):141-51. [PMID:6647010]

22. Bernstein NA. On dexterity and its development. In: Latash ML, Turvey MT, Bernstein NA, editors. Dexterity and its development. Mahway (NJ): L. Erlbaum Associates; 1996. p. 3-244.

23. Latash LP, Latash ML. A new book by N. A. Bernstein: “On dexterity and its development." J Mot Behav. 1994; 26(1):56-62. [PMID:15757835] http://dx.doi.org/10.1080/00222895.1994.9941662

24. Beek PJ. Toward a theory of implicit learning in the perceptual-motor domain. Int J Sport Psychol. 2000;31: 547-54.

25. Bongers RM, Zaal FT, Jeannerod M. Hand aperture patterns in prehension. Hum Mov Sci. 2012;31(3):487-501. [PMID:22130470] http://dx.doi.org/10.1016/j.humov.2011.07.014

Submitted for publication September 28, 2011. Accepted in revised form February 14, 2012.

This article and any supplementary material should be cited as follows:

Bouwsema H, Kyberd PJ, Hill W, van der Sluis CK, Bongers RM. Determining skill level in myoelectric prosthesis use with multiple outcome measures. J Rehabil Res Dev. 2012;49(9):1331-48.

http://dx.doi.org/10.1682/JRRD.2011.09.0179

ResearcherID: Corry K. van der Sluis, MD, PhD: C-1102-2012; Raoul M. Bongers, PhD: C-1094-2012

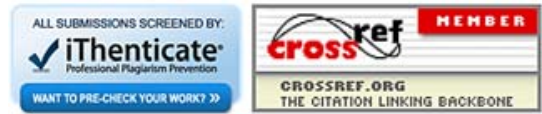


